\title{
The Relationship Between Rural Women's Health-Related Quality of Life and Domestic Violence
}

\author{
Seyed Ramin Ghasemi ${ }^{1}$; Sohyla Reshadat ${ }^{2}$; Nader Rajabi-Gilan ${ }^{1,}$; Yahya Salimi ${ }^{1}$; Masoud \\ Norouzi $^{1}$ \\ ${ }^{1}$ Social Development and Health Promotion Research Center, Kermanshah University of Medical Sciences, Kermanshah, IR Iran \\ ${ }^{2}$ Department of Pediatric, Social Development and Health Promotion Research Center, Kermanshah University of Medical Sciences, Kermanshah, IR Iran \\ ${ }^{*}$ Corresponding author: Nader Rajabi-Gilan, Social Development and Health Promotion Research Center, Kermanshah University of Medical Sciences, Kermanshah, IR Iran. \\ E-mail:rajabi_nader@yahoo.com
}

Received: March 3, 2014; Accepted: May 18, 2014

Background: Nowadays, by development of societies, health related quality of life has become a very important issue. Traditionally for health assessment, some indexes such as; morbidity, mortality, and life expectancy, have been taken into consideration but these factors are not able to assess life satisfaction.

Objectives:The present study was aimed to investigate the relationship between rural women's health-related quality of life(HRQOL) and domestic violence.

Patients and Methods: This cross-sectional study was carried out in the rural districts of Kermanshah, Iran, 2012. Using multistage cluster sampling, 394 women were selected. They completed WHOQOL-BREF and Conflict Tactics Scale (CTS) questionnaires. Data analyzed by SPSS 16, using Pearson correlation and regression tests.

Results: The mean scores of total QOL were $55.8 \pm 12.9$. There was significant inverse correlation between domestic violence dimensions and all health-related quality of life domains $(\mathrm{P}<0.01)$.

Conclusions: Domestic violence can affect rural women's health-related quality of life negatively. Regarding the hidden nature of domestic violence and its presence in all communities, taking into consideration policies to reduce violence through legal education and raising women awareness can positively affect women's quality of life.

Keywords: Quality of Life; Women; Domestic Violence; Development

\section{Background}

Nowadays, by development of societies, health related quality of life has become a very important issue [1]. Traditionally for health assessment, some indexes such as; morbidity, mortality, and life expectancy, have been taken into consideration but these factors are not able to assess life satisfaction [2]. There is a belief that having better health measurements needs to considering estimations of welfare and wellbeing. This issue helps policy-makers to have better planning and effective interventions by considering individuals' views and emotions toward their quality of lives [3]. The increasing importance of quality of life, particularly among female population, resulted in conducting many studies in this field. For instance, studies in total Iranian population [4] and some other studies in various other countries [3] had indicated poorer quality of life in females compared to males.

Domestic violence as the most common kind of violence against women [5] negatively affects their quality of life [6]. Statistics of WHO (World Health Organization) indicates that $16 \%$ to $52 \%$ of women are victims of violence imposed by their partners [7]. Other studies indicate that
$18-67 \%$ of women in developing countries have at least once reported physical abuse [8]. Leung et al. in a study on Obstetric/Gynecological patients found that the mean quality of life domain scores among the abused victims were significantly lower in comparison with none abused persons [6]. Also Coker et al. observed this relationship in high school students [9].

Women, living in rural communities experience various forms of discrimination and deprivation, since; economic activities they undertake do not generate tangible income, and as a result limits their access and possession over resources [10]. Also, low levels of rural development, in comparison with cities, can increase these deprivations for rural women. So they are in risk of reduced quality of life.

\section{Objectives}

Therefore, considering the need to examining research's aim in local environment of Iran's rural areas, because of socio-cultural differences with other countries, the pres-

Copyright (C) 2015, Zahedan University of Medical Sciences. This is an open-access article distributed under the terms of the Creative Commons Attribution-NonCommercial 4.0 International License (http://creativecommons.org/licenses/by-nc/4.0/) which permits copy and redistribute the material just in noncommercial usages, provided the original work is properly cited. 
ent study was conducted with aim of surveying the association between rural women's health related quality of life and domestic violence.

\section{Patients and Methods}

This cross-sectional study has been conducted from June to September 2012 on a sample size of 420 rural women resided in Kermanshah, Iran. Samples were selected by multi-stage clustered sampling. From Kermanshah villages, in 3 stages, 20 villages were selected and based on the number of households in each village, 420 households were systematically selected. In this part, one woman from each household was randomly selected and she completed the research questionnaires. In every case, the aim of study explained for respondents and their consent were obtained. The including criteria in this study was having at least one year history of resident in village and having no mental or physical disability.

After eliminating incomplete questionnaires, 394 cases remained in the study (responsiveness rate: 93.8\%). WHOQOL-BREF Questionnaire (with 26 items) was used for assessing Quality of life variable. In Iran, this questionnaire has been demonstrated to be valid and reliable [11]. It consists of four domains: "Physical Health", "Psychological Health", "Social Relations" and "Environmental Health" while applying Five-Point Likert Scale. The scores from zero to 100 were separately calculated for each domain. Conflict Tactics Scale (CTS) was applied to assess domestic violence [12]. It assesses exposure to violence within the last one year in 3 dimensions of: "Physical", "Emotional", and "Neglect". The sum of all these three will measure the total violence. Responds were collected by applying a Seven-Point Scale ranged from "Never" to "20 Times". In Iran, the Persian version of the scale is approved in terms of reliability and validity [12]. Also, Numerical Taxonomy method has been applied to assess rural development level. Following parameters were applied to assess rural development level: literacy status of the rural residents, employment status of the rural residents, roads condition (paved or unpaved), Distance from the city, having of rural health care center, cultivated land area, implementation of rural HADI projects (i.e. a national project to pave roads, improve sidewalks and pave streets and measures as such in villages). After the analysis, villages were classified in three groups as; "Developed" (4 villages), "Semi Developed" (10 villages) and "None-Developed" (6 villages).

Also other variables such as: "age, organizational support, health situation" (having or not having a chronic or acute illness in research time), ownership (having or not having ownership on money, gold, land or private house, etc.), education level" and "marriage status" were asked from samples. Analysis was done by SPSS 16, using the Pearson Correlation and multiple linear regression analysis tests.

\section{Results}

The mean age of participants was $32.94 \pm 8.98$ years and $81.7 \%(\mathrm{n}=318)$ were married. Of all $46.4 \%$ of respondents had an acute or chronic illness in the research time and $18.1 \%$ have had ownership on money, gold, etc. In terms of development level; villages were classified to three groups as such; 4 villages out of 20 samples were rated developed, 10 villages semi-developed, and 6 villages underdeveloped.

The mean score of total QOL was $55.82 \pm 12.97$. This mean score for physical, psychological, social relations and environmental health domain were $61.55 \pm 15.98$, 53.22 $\pm 16.68,60.58 \pm 17.53$ and $47.94 \pm 16.04$ respectively. Pearson correlation test results indicated that there was an inverse and significant correlation between "overall violence" with total quality of life $(\mathrm{P}<0.01)$. Also there were some significant inverse correlation between violence subscales and QOL domains (Table 1). Considering the association between different variables of study (health situation, education level, organizational support, age, rural development level, marriage status, ownership, emotional and physical violence and neglect) and total quality of life, regression test was conducted to address the relative importance of each variable. Based on the (Table 2), out of all the above mentioned variables, the variables of "health situation, education level, development level, marriage status, emotional violence and ownership" were remained in the regression analysis. Also the conducted variance analysis indicates a meaningful "F" in 0.001 levels.

Table 1. Pearson Correlation Between Violence and Total Quality of Life and its Domains

\begin{tabular}{|c|c|c|c|c|c|}
\hline \multirow[b]{2}{*}{ Violence Type } & \multicolumn{4}{|c|}{ WHOQOL-BREF Domains } & \multirow{2}{*}{$\begin{array}{l}\text { Total Quality of } \\
\text { Life }(\mathbf{r})\end{array}$} \\
\hline & $\begin{array}{l}\text { Physical Health } \\
\text { Domain }(\mathbf{r})\end{array}$ & $\begin{array}{c}\text { Psychological } \\
\text { Health Domain (r) }\end{array}$ & $\begin{array}{l}\text { Social relation } \\
\text { Domain }(\mathbf{r})\end{array}$ & $\begin{array}{c}\text { Environmental } \\
\text { Health Domain }(r)\end{array}$ & \\
\hline Overall violence & $-0.121^{a}$ & $-0.311 \mathrm{~b}$ & $-0.268^{b}$ & $-0.337^{b}$ & $-0.335^{b}$ \\
\hline Physical violence & -0.089 & $-0.234^{b}$ & $-0.208^{b}$ & $-0.285^{b}$ & $-0.264^{b}$ \\
\hline Emotional violence & -0.104 & $-0.282^{b}$ & $-0.260^{b}$ & $-0.308^{b}$ & $-0.307^{b}$ \\
\hline Neglect & $-0.106^{a}$ & $-0.279^{b}$ & $-0.141^{b}$ & $-0.252^{b}$ & $-0.252^{b}$ \\
\hline
\end{tabular}

a $\mathrm{P}<0.05$.

$\mathrm{b} \mathrm{P}<0.01$. 
Ghasemi SR et al.

Table 2. Predictors of Total HR-QOL by Multiple Linear Regression Analysis a

\begin{tabular}{|c|c|c|c|c|c|c|}
\hline \multirow{2}{*}{ Predictors } & \multirow{2}{*}{ B } & \multirow{2}{*}{ Std. Error B } & \multirow{2}{*}{ Standardized Beta } & \multirow{2}{*}{ P-Value } & \multicolumn{2}{|c|}{ 95\% Confidence Interval for B } \\
\hline & & & & & Lower Bound & Upper Bound \\
\hline Health situation & 9.40 & 1.27 & 0.372 & $<0.001$ & 6.90 & 11.91 \\
\hline \multicolumn{7}{|l|}{ Education Level $^{\mathrm{b}}$} \\
\hline Elementary & 0.209 & 1.85 & 0.008 & 0.910 & -3.44 & 3.86 \\
\hline $\begin{array}{l}\text { High/Guidance } \\
\text { School }\end{array}$ & 4.31 & 1.77 & 0.117 & 0.015 & 0.830 & 7.80 \\
\hline Diploma & -0.570 & 2.37 & -0.012 & 0.810 & -5.24 & 4.10 \\
\hline Over diploma & 8.23 & 3.35 & 0.125 & 0.015 & 1.63 & 14.82 \\
\hline \multicolumn{7}{|l|}{ Development Level $^{\mathrm{C}}$} \\
\hline Semi-Developed & 4.86 & 1.35 & 0.172 & $<0.001$ & 2.20 & 7.53 \\
\hline Non-Developed & 0.933 & 2.08 & 0.022 & 0.655 & -3.17 & 5.04 \\
\hline \multicolumn{7}{|l|}{ Marriage Status $^{\mathrm{d}}$} \\
\hline Married & 3.81 & 1.84 & 0.116 & 0.040 & 0.180 & 7.45 \\
\hline Widow & -7.61 & 3.63 & -0.115 & 0.037 & -14.76 & -0.457 \\
\hline Emotional Violence & -0.352 & 0.064 & -0.266 & $<0.001$ & -0.478 & -0.227 \\
\hline Ownership & 2.59 & 1.55 & 0.081 & 0.095 & -0.454 & 5.65 \\
\hline Constant & 48.16 & 2.08 & & $<0.001$ & 44.06 & 52.26 \\
\hline
\end{tabular}

${ }^{a}$ Adjusted $\mathrm{R}^{2}$ is 0.356 .

b Reference Group = Illiterate.

c Reference Group = Developed.

$\mathrm{d}$ Reference Group $=$ Single.

\section{Discussion}

Our findings showed that overall violence have had a negative correlation with total quality of life and its four domains. This means that in target group of the study, individuals who were exposed to domestic violence more than others, have poorer levels of quality of life. Similarly, other studies have pointed out a lower quality of life in women who were victims of intimate partner violence [6].

This study has shown that, all subscales of domestic violence include neglect, emotional violence and physical violence had most negative correlations with psychological health domain of quality of life in comparison with other domains. Similarly, other studies indicated that women who were exposed to intimate partner violence were considerably hurt in emotional and mental dimensions [13]. Therefore it can be concluded that psychological impacts of domestic violence for rural women health are destroyer than other impacts of it.

It was also shown that, variables such as; health situation, education level, development level, marriage status, emotional violence and ownership were remained in total quality of life equation and explained almost 36\% of its variations. So, it was predictable that health situation variable have had an impact on quality of life and ill women had worse status in total QOL that this finding supports results of Arslantas et al. study [14]. Also Shams Alizade et al. [4] and Arslantas et al. [14] in their studies showed that education level have correlated with quality of life and this supported our findings.

Among various dimensions of domestic violence, only emotional violence remained in the equation while having significant negative correlation with total quality of life. Similar findings were observed in other studies [6, 15]. Regarding the hidden nature of domestic violence and its presence in all communities and social strata [15], adopting appropriate policies to reduce violence through legal education and raising rural women awareness can positively affect women's quality of life.

Finally, a number of limitations need to be considered. First, like other questionnaire based studies it is possible that their responds might be affected by emotional and situational status of respondents. Also some cultural and sub-cultural indicators might be affective on the study results that could not be controlled in this study. In other hand, the strength of this study is that, we considered macro variables such as rural development level besides micro variables. It is suggested that future studies consider larger population (at regional or national level), all rational/dialectal groups and cultural aspects of target population.

\section{Acknowledgements}

The researchers are extremely grateful to the Kerman- 
shah University of Medical Sciences for financial support (Project code: 91290 ).

\section{Authors' Contributions}

All authors had equal role in design, work, statistical analysis, and manuscript writing.

\section{Funding/Support}

Kermanshah University of Medical Sciences, Social Development and Health Promotion Research Center.

\section{References}

1. Zhao J, Li Y, Wu Y, Zhou J, Ba L, Gu X, et al. Impact of different contraceptive methods on quality of life in rural women of the Jiangsu province in China. Contraception. 2009;80(2):180-6.

2. Muldoon MF, Barger SD, Flory JD, Manuck SB. What are quality of life measurements measuring? BMJ.1998;316(7130):542-5.

3. Sabbah I, Drouby N, Sabbah S, Retel-Rude N, Mercier M. Quality of life in rural and urban populations in Lebanon using SF-36 health survey. Health Qual Life Outcomes. 2003;1:30.

4. Shams Alizadeh N, Mohsenpour B, Ghaderi E, Razaei F, Delavari A. Quality of life in 15-64 years old people in Kurdistan province, western part of Iran. J Fundam Ment Health. 2010;12(45):448-56.

5. Flury M, Nyberg E, Riecher-Rossler A. Domestic violence against women: definitions, epidemiology, risk factors and consequences. Swiss Med Wkly. 2010;140:w13099.
6. Leung TW, Leung WC, Ng EH, Ho PC. Quality of life of victims of in timate partner violence. Int J Gynaecol Obstet. 2005;90(3):258-62.

7. Amoakohene MI. Violence against women in Ghana: a look at women's perceptions and review of policy and social responses. Soc Sci Med. 2004;59(11):2373-85.

8. Nasir K, Hyder AA. Violence against pregnant women in developing countries: review of evidence. Eur J Public Health 2003;13(2):105-7.

9. Coker AL, McKeown RE, Sanderson M, Davis KE, Valois RF, Huebner ES. Severe dating violence and quality of life among south carolina high school students. Am J Prev Med. 2000;19(4):220-7.

10. Soroushmehr H, Rafiei H, Kalantari K, Shabanali-Fami H. The survey of socioeconomic base of rural women and its related factors (case study: Hamadan city). Rural Res. 2010;1(1):143-65.

11. Jahanlou AS, Karami NA. WHO quality of life-BREF 26 questionnaire: reliability and validity of the Persian version and compare it with Iranian diabetics quality of life questionnaire in diabetic patients. Prim Care Diabetes. 2011;5(2):103-7.

12. Halabi M, Rassoulzadeh-Aghdam S. The effect of order and conflict in the family upon violence against children. Iran J Sociol. 2002;4(2):26-54

13. Wittenberg E, Joshi M, Thomas KA, McCloskey LA. Measuring the effect of intimate partner violence on health-related quality of life: a qualitative focus group study. Health Qual Life Outcomes 2007;5:67.

14. Arslantas D, Unsal A, Metintas S, Koc F, Arslantas A. Life quality and daily life activities of elderly people in rural areas, Eskisehir (Turkey). Arch Gerontol Geriatr. 2009;48(2):127-31.

15. Maleki A, Nezhadsabzi P. Social capital of families and domestic violence; a case study in Khorramabad. Iran J Soc Probl. 2010;1(2):31-53. 